\title{
Aproximaciones al conocimiento de lo social: entre teoría social y sociología
}

\author{
APPROACHES TO THE KNOWLEDGE OF THE SOCIAL: BETWEEN SOCIAL THEORY AND SOCIOLOGY
}

Felipe Torres (felipe.torres@udp.cl) Instituto de Humanidades, Núcleo de Teoría Social, Universidad Diego Portales (Santiago, Chile)

\begin{abstract}
Is there a distinction between social theory and sociology? Perhaps one of the most general features in sociological thinking is that it is an inquiry to develop holistic explanations for social reality. In this sense, there is a kind of universality of social knowledge in its scientific and philosophical dimensions, and is one of its main purposes for the operation of sociology as a "science of modernity". Next, I will develop a brief reconstruction of meaning which is attributed to science in the modern world, followed by the emergence of an specialized explanation of social reality under the name of social theory, as a result of philosophical conclusions that finish it with Hegel on the one side, and it focuses on a differentiated scientific knowledge as a product of modernity itself, on the other hand. Finally, and following this, I will establish the specific role played by sociology and social theory in this context, by considering that the first describes itself as a science of society-modernity and the second has a critical direction to sociability answers and is specifically linked with political-normative approaches.
\end{abstract}

Keywords: social theory, sociology, modernity, universalism, reason, enlightenment.

\section{Resumen}

¿Existe una diferencia entre teoría social y sociología? ¿Se trata de aproximaciones diferentes a un mismo problema o de problemas con tradiciones diferentes que suelen confundirse? Probablemente el elemento que más caracteriza al pensar sociológico sea su búsqueda o pretensión por desarrollar explicaciones holísticas de la realidad. En este sentido la universalidad en el conocimiento sobre lo social en particular resulta uno de los temas de base para el operar de la sociología en tanto ciencia de la sociedad. A continuación y a través de la observación de pasajes específicos de la tradición inaugurada con Hegel, se desarrollará, por un lado, una breve reconstrucción del sentido que se le atribuye a la ciencia en el mundo moderno, seguido, por otro, de la emergencia de un saber especializado de la realidad social bajo el nombre de teoría social de una parte y sociología de otra. Siguiendo lo anterior, se establecerá el papel específico que juega la sociología y la teoría social, entendiendo que a la primera se le entrega el apelativo de ciencia de la sociedad-modernidad y a la segunda una orientación más marcada a las preguntas por la sociabilidad y específicamente vinculada a orientaciones político-normativas.

Palabras clave: teoría social, sociología, modernidad, universalismo, razón, ilustración. 


\section{Introducción}

En este artículo se abordarán las posibilidades de una separación conceptual entre las definiciones de teoría social y sociología. A través de una revisión histórica se pueden rastrear los orígenes de discursos autónomos sobre lo social que dan cuenta de las diferentes trayectorias que son posibles de distinguir para la teoría social y la sociología desde el comienzo y hasta nuestros días. Esto último será particularmente notorio en la forma que ambos saberes se aproximan o relacionan con pretensiones de universalidad. Para eso nos serviremos de ciertos análisis de Max Weber y autores de la Escuela de Frankfurt (Max Horkheimer, Herbert Marcuse y Jürgen Habermas) donde la distinción puede observarse, para finalmente concluir con ciertas consecuencias de una y otra aproximación en el contexto contemporáneo.

Cuando hablamos de la separación de dos discursos sobre lo social, es posible partir constatando que las diversas esferas de lo social pueden abordarse sin necesariamente aunar criterios dentro de un marco de sentido general y desde allí concebir cada esfuerzo explicativo como una parte específica de la sociedad, con relativa autonomía y separación de las demás. Es por esto que a priori tal separación no posee un carácter negativo, el cual por lo demás tampoco se buscará desmentir o corroborar en este artículo. Sin embargo, cuando tal distinción aparece o se hace explícita, las explicaciones desarrolladas corren el riesgo de no cumplir los estándares esperados de un discurso sobre lo social-sociedad en su conjunto, en la medida que éstos discursos desde su origen buscan conectar lo que se percibe como particular en un marco de relaciones más general.

En palabras de Theodor W. Adorno: "sin desconocer la importancia de poner énfasis en ciertos elementos característicos de cierta sociedad para comprender a la misma, es un precepto sociológico no menor que ninguna de dichas consideraciones puede agotar la explicación de la totalidad social" (2001:10). Con respecto a la primera parte de la cita, ya lo decía Weber en 1919: "En la actualidad la situación interior de la vocación científica está condicionada, en primer lugar, por el hecho de que la ciencia ha entrado en un estadio de especialización antes desconocido y en el que se va a mantener para siempre... En nuestro tiempo la obra realmente importante y definitiva es siempre obra de especialistas" (Weber 2000:192).

Volviendo a Adorno, en ese sentido si de lo que se trata es de una ciencia o teoría de lo social-sociedad, se espera que la sociología aporte respuestas de conductas generales al interior de un conocimiento que dé cuenta de las razones que llevan a desarrollar modos de ser y actuar específicos en condiciones históricas determinadas. Por su parte Max Weber argumenta contra las explicaciones atomizadas (es decir, no universales) de lo social que "toda historia bancaria que sólo adujera motivos económicos para su explicación, resultaría tan segmentada como una explicación de la capilla Sixtina a partir de las bases socioeconómicas de la vida cultural en tiempos de su creación; como también derivar el capitalismo de ciertas transformaciones de los contenidos religiosos de la conciencia o bien derivar una estructura política de determinados condicionamientos geográficos" (Weber 1997:35). Algunos comentaristas creen que esto es incluso más radical y que el conocimiento moderno trataría más fundamentalmente de un proceso onmiabarcante: "Weber se refiere a un «proceso de intelectualización al que estamos sometidos desde hace milenios» [...] repitiendo la idea de un poder racionalizador metahistórico que opera sobre el individuo" (Weisz 2011:118). La consecuencia de lo anterior es que para la medición de la importancia que debemos conceder a los condicionamientos sociales, resulta decisivo saber a qué tipo de causas deben atribuirse aquellos elementos específicos del fenómeno en cuestión que nos importa, a los que concedemos importancia en un caso particular. 
Tomando lo anterior como punto de partida, a continuación desarrollaremos una reflexión sobre la particularización que el conocimiento ha experimentado como fruto de una realidad moderna que se presenta como diferenciada y a partir de allí abordar lo que significa una pretensión de conocimiento universal. A la luz de los argumentos sobre el sentido de la ciencia en Weber, y de los rastreos de la evolución social y de la razón efectuados por Marcuse, Horkheimer y Habermas, veremos a qué fenómenos particulares responde esta situación y cómo ella misma contribuye a elaborar discursos en torno a lo social bajo parámetros sociológicos de una parte y teórico sociales de otro.

\section{Surgimiento de discursos sobre lo social-sociedad}

En un texto de 1941 titulado Reason and Revolution Herbert Marcuse analiza cómo el acontecer filosófico del siglo XIX se inserta, a su juicio por vez primera, en la observación de las condiciones sociales que forman el marco general en el cual opera toda reflexión filosófica. Puesto que con Hegel la filosofía habría alcanzado uno de sus puntos culmines, la realización de la razón ya no puede mantenerse en el plano trascendental en que se había movido durante el tiempo de la metafísica. La Historia ya había adquirido la madurez suficiente como para pensar en una labor diferente del saber.

Analizando a Hegel, Marcuse concluye que "las ideas filosóficas básicas habrían experimentado su realización en la forma específica que el Estado y la sociedad contemporánea habían asumido, convirtiéndose así en el centro de un nuevo interés teórico: la filosofía había evolucionado hacia una teoría social" (Marcuse 1994:247). De esta manera, puesto que las condiciones sociales se perciben como las indicadas para la transformación de la realidad irracional en una racional, es que se comienza a desarrollar un saber especializado en relación al área de las relaciones humanas con vistas a la evaluación del componente de razón presente en ellas.

Para Marcuse, Hegel es el primer filósofo que rompe con la tendencia a la introversión -entendida como la compatibilización de la realidad en el interior- y a proclamar la realización de la razón en y a través de las instituciones políticas y sociales dadas: "Hegel fue el último en interpretar el mundo como razón, sometiendo tanto la historia como la naturaleza a las normas del pensamiento y de la libertad. Al mismo tiempo, Hegel reconocía en el orden político y social que el hombre había alcanzado, la base sobre la que habría de realizarse la razón. Su sistema condujo a la filosofía a un umbral de su propia negación, constituyendo así el único vínculo entre la vieja y la nueva forma de la teoría crítica, entre la filosofía y la teoría social" (Marcuse 1994:249). La dialéctica llevó a la filosofía a chocar con la realidad, dando como resultado la disolución del mundo armónico de objetos fijos puesto por el sentido común y el reconocimiento de que la verdad buscada por la filosofía es una totalidad de profundas contradicciones (Marcuse 1994:253). Como proceso reflexivo anclado en la constitución de la realidad, la dialéctica es para Marcuse el paso decisivo de la consideración de una filosofía especulativa a una comprometida con la realización de la razón en la realidad. De ello se desprende que el impacto de la filosofía hegeliana en la teoría social, y la función específica de la moderna teoría social, sólo pueden llegar a ser comprendidas a partir de la forma plenamente revelada de la filosofía de Hegel y de sus tendencias críticas, tal como pasaron a la teoría marxista. Sin embargo no ahondaremos en la adopción específica hecha por Marx ya que no interesa para nuestros efectos mayormente su desarrollo, sino más bien cómo ello forma parte de la generación de la teoría social como paso a la ruptura de una visión integral de la realidad.

Este interés filosófico por la transformación de la realidad se basa en la idea de que tanto la vida social como natural se rigen por un principio racional que le otorga su organización y mantención. Una vez considerado esto es necesario generar en las propias instituciones humanas la proliferación de un orden 
racional. Marcuse es un tanto ambiguo para establecer cuál es la primera de las teorías sociales propiamente tal. Si bien menciona al marxismo como heredero legítimo e hijo primigenio de este estado de cosas, el positivismo en su vertiente comteana también es señalada como punto de partida para una consideración inicial de la teoría social, aunque también, dicho sea de paso, lo es para la sociología -mucho más profundamente que el marxismo. Más allá de eso, y siguiendo la línea argumentativa que prefiere Marcuse, éste anuncia al marxismo como la primera teoría social que continúa la herencia racionalista que nace con Hegel.

Siguiendo la idea del "extrañamiento del hombre por el hombre" Marx rescata a Hegel en su demostración de lo que en ello juega el papel del trabajo y el proceso de reificación. Sólo que "la salida hegeliana relega la reconciliación de las contradicciones en el espíritu absoluto" (Marcuse 1994:256), dando a entender que la relación entre teoría y realidad está consumada. En este sentido Hegel parece haber caído en una falacia autorreferente: "La verdad, según Hegel, es un todo que tiene que estar presente en cada uno de los elementos, de modo que si un elemento material o un hecho no pueden ser conectados con el proceso de la razón, la verdad del todo queda destruida. Según Marx tal elemento existía y era el proletariado. La existencia del proletariado contradice la supuesta realidad de la razón, ya que representa toda una clase que demuestra la negación misma de la razón" (Marcuse 1994:257). Este argumento es el que da pie a que la filosofía ya no sea la encargada de hacer entrar la razón en el mundo pues su planteamiento es desde tiempo atrás, ostensiblemente estático. Una nueva teorización debe hacerse cargo de este remanente de praxis que la filosofía no ha sabido concretar: la teoría social. Por tanto, "la crítica de la sociedad no puede ser llevada a cabo por la misma doctrina filosófica, sino que se convierte en tarea de la práctica socio-histórica" (Marcuse 1994:258). La teoría social por tanto, pasa a ser percibida como la concordancia entre razón y práctica social, estableciendo en el objeto de la teoría social mucho más énfasis en la aplicación práctica. Sin embargo, esa suposición no se presenta exenta de una contraparte.

Desde el existencialismo de Kierkegaard "se realiza un ataque a la suposición universalista de la razón, en pos de una consideración individual de la búsqueda de la felicidad" (Marcuse 1994:263). En ese sentido lo que realmente importa al individuo es su inmediatez en la supresión de la angustia y no en la organización práctica de la sociedad. Esto lleva a afirmar que las leyes no se fundan en cualidades universales del hombre en las que resida la razón; expresan más bien las necesidades de personas individuales cuyas vidas se regulan de acuerdo a sus requerimientos existenciales (Marcuse 1994:264). Este antirracionalismo entendido como oposición a una idea de razón objetiva, pone en tela de juicio los universalismos.

Sin embargo, no es esta postura la más radicalizada o más importante en contra de la conciencia práctica o material; más allá de esta crítica individualista a la razón, existe una propuesta más profunda en contra de una idea de teoría social anclada en la transformación de la realidad. Cuando Marcuse se propone intentar mostrar cómo el desarrollo interno de la filosofía occidental exigía la transición hacia una teoría de la sociedad, pone especial atención a lo que ocurre después del último gran sistema idealista. Luego de Hegel se generaría una disputa entre una filosofía positiva y una filosofía negativa, esta última en la línea del trascendentalismo. Por el contrario, la primera se rebelaba contra la visión de una realidad supeditada a categorías a priori, debiendo preservarse la independencia de los hechos, por consiguiente el razonamiento debía estar orientado a una aceptación de lo dado.

De esta forma, "la filosofía positiva se esforzaba por contrarrestar el proceso crítico que encerraba la «negación» filosófica de lo dado, y por integrar a los hechos la dignidad de lo positivo" (Marcuse 1994:318). Marcuse establece que la moderna teoría social recibió su mayor impulso desarrollista durante el siglo XIX, del positivismo. Esta filosofía positiva se refiere a la síntesis de todo el conocimiento empírico 
ordenado dentro de un sistema de progreso armonioso, que sigue un curso inexorable, inevitable. Así la sociología positiva, que encontraría en el Cours de philosophie positive de Auguste Comte de 1853 "su máximo exponente, se preocupará de la investigación de los hechos antes que de ilusiones trascendentales, del conocimiento útil antes que de la contemplación ociosa, de la organización antes que de la destrucción y la negación" (Marcuse 1994:332). Posteriormente esto se vería desarrollado de manera más elaborada bajo el nombre directo de sociología en la obra de Gabriel Tarde (1999, original de 1893) e, incluso, Émile Durkheim (2007, original de 1894).

De esta manera, Comte se vuelve propulsor de un tipo de racionalidad que se ve ligada a la utilización especializada del conocimiento en vistas a la situación que vive el saber humano: las grandes explicaciones de la metafísica ya no son la tarea a continuar, pues como el propio Hegel menciona, la razón debe dar paso a un nuevo tipo de conocimiento, esta vez más ligado al dominio de la realidad que al plano especulativo. Esta filosofía positiva se adhiere a un argumento en favor de la entrada progresiva de la razón en el mundo para afirmar que el cambio radical no conduce a la efectiva realización humana, pues la naturaleza material y social poseen sus propias leyes evolutivas que por medio de la intervención humana no harían más que perder su sabio flujo. En palabras de Marcuse: "La oposición positivista al principio de que los hechos de la experiencia tienen que justificarse ante el tribunal de la razón, impedía, sin embargo, una interpretación de estos "datos» en términos de una crítica comprensiva de lo dado" (1994:319). En última instancia, la filosofía positiva habría facilitado la capitulación del pensamiento ante lo efectivo y manifestando el poder de persistir en la experiencia. Comte declararía explícitamente, señala Marcuse, que el término "positivo», con el cual designaba su filosofía, implicaba una educación del humano para que éste tomase una actitud positiva, es decir, afirmativa, en relación al estado de cosas existente. La filosofía positiva afirmaba el orden existente en contra de los que sostenían la necesidad de negarlo a través de su transformación radical. De esta manera, la emergente sociología excluirá todo impulso tendiente a derrocar o negar el orden presente.

En este punto se desarrolla una primera suerte de desprestigio a una razón integradora, pues se considera por un lado que la realidad presente posee condiciones racionales suficientes, y por otro se piensa que la labor científica no se corresponde con la intervención como orientación en las relaciones humanas y con su entorno. Con ello la actividad del pensamiento queda reducida a mera receptividad. En palabras de Marcuse: "La convicción fundamental del idealismo había sido que la verdad no le es dada al hombre de una fuente externa, sino que se origina en el proceso de la interacción entre pensamiento y realidad, teoría y práctica. La función del pensamiento no era simplemente la de recolectar, comprender y ordenar los hechos, sino también la de aportar una cualidad que hiciese posible dicha actividad, cualidad que, por ende, era un a priori con respecto a los hechos" (1994:334). Esta espontaneidad del pensamiento es rechazada por el positivismo, pues se cree más bien en la receptividad del pensar en tanto receptáculo de las condiciones externas objetivas que dan pie al saber.

Nuevamente Marcuse identifica con Comte al paradigma del antimaterialismo. Comte subraya repetidamente «los graves y amenazantes peligros» que acompañan al "predominio de puras consideraciones materiales» en la teoría y práctica social. De esta manera los intereses íntimos de la sociología de Comte son marcadamente más antimaterialistas que el idealismo hegeliano: «las dificultades sociales más importantes son hoy esencialmente morales y no políticas», afirmaba Comte (2014).

Sin embargo, a la luz de lo que se ha venido tratando, podría decirse que, contrariando a Marcuse, Comte tiene razón al señalar que la teoría social se juega la orientación de la sociedad en un plano más bien ético. Como hemos venido observando el plano material adquiere, incluso en Hegel, un nivel de desarrollo 
suficiente para la satisfacción de las necesidades humanas, cuestión que, por lo demás, se ve corroborada con la instrumentalización de la razón en el diagnóstico weberiano y horkheimeriano; por tanto el plano normativo es el punto que flaquea en un contexto de conocimiento tecnificado. Si relacionamos la filosofía positiva que surge de Hegel, con la pérdida del paradigma de una razón objetiva como integradora de la totalidad del sentido social, en pro de la dominación técnica de la realidad natural y social, podemos ver que el diagnóstico comteano no está del todo alejado de planteamientos como el de Marx o la Escuela de Frankfurt (cien años después) pues en el fondo lo que ocurriría es que el conocimiento objetivo ha sido escindido de todo plano normativo, tratando a ambos como esferas diferenciadas e incluso excluyentes. Esto no niega la postura afirmativa del positivismo comteano, como tampoco ignora el acento político de las propuestas herederas de la filosofía negativa. Más bien conecta un diagnóstico que parece estar presente tanto en el planteo positivo-descriptivo como en el negativo-normativo, a saber, el destino de época define su futuro en la orientación del conocimiento.

Así, con la preponderancia de un tipo de filosofía, el proceso de hacer compatible la teoría social naciente con las condiciones existentes, lleva al positivismo a excluir todos aquellos elementos de trascendencia que vayan más allá de la situación de lo dado; esto, por tanto, conduce a la estabilización de un discurso sociológico: puesto que no existen verdades trascendentes al plano de la experiencia, toda verdad es resultado de su época, o al menos no responde a un ideal unificador de la realidad por medio de una razón ahistórica. De esta manera se distingue el primer hilo explicativo de los motivos que nos llevan a la parcelación del conocimiento entre una sociología eminentemente descriptiva y una teoría social normativa.

Siguiendo a Marcuse, la filosofía de lo social da un paso más en su independencia de marcos explicativos más generales. Al igual que en Comte, la filosofía social se vuelve ciencia bajo el nombre de sociología y reclama para sí un tipo de verdad particular en lo referente a las relaciones sociales. Así se obtiene una nueva ciencia que viene a replicar el fenómeno producido en otras áreas del conocimiento, a saber, la especialización del saber en objetos de estudio diferenciados. La filosofía se transforma en una carta sinóptica en donde pueden sopesarse los diversos saberes. Nuevamente toda pretensión de trascendentalidad es considerada inútil. Incluso la filosofía, aquella "carta sinóptica», debería acomodarse al plano del conocimiento factual que entregasen las nuevas ciencias especializadas.

Un elemento que otorga un grado de complejidad no menor es el hecho de que la sociología en sus albores se percibe como una parte integrante del conocimiento que se genera también en las otras esferas de estudio humano y natural -biología, física, antropología, etc. - pretendiendo de esta manera unificar el saber bajo una interconectividad de ciencias emergentes, caso ejemplar es el intento de Ludwig von Bertalanffy y la Teoría General de Sistemas. Así la apuesta positiva logra desarrollar una explicación integral de la realidad, a partir de los conocimientos parcelados de las diversas esferas que la componen. En otras palabras, desde que un discurso social identifica y delimita un objeto de estudio específico y propio, pasa a convertirse en una ciencia de la sociedad -sociología- con pretensiones de neutralidad y especificidad en su conocimiento, pero al mismo tiempo de aplicación objetiva en la medida que se conecta con el saber universal. Por tanto esta nueva ciencia positiva alojaría en su interior una semilla de integración y universalidad en el conocimiento, solo que ella no viene dada por una trascendencia, sino por la inmanencia del hecho dado. A este aspecto la postura dialéctica y que, como veremos, se sitúa más cerca de la teoría social, opone la consideración de que las "relaciones sociales abarcan y condicionan todas las esferas de la existencia y del pensamiento" (Marcuse 1994:365), no pudiendo reducir la teoría social a una especialidad científica, pues la sociedad es una modalidad de las relaciones humanas incluyendo las relaciones con la naturaleza- y no la totalidad de éstas. 
Un dato que ayudaría a comprender más acabadamente la conexión entre sociología y otras esferas del saber social que posibilitan fortificar su emergencia, radica en la relación existente entre el principio universalista que suponen las teorías críticas al derecho natural y la pretensión universal que asimilan tanto ellas como la naciente teoría social de la cual hemos venido tratando. En este sentido se puede conectar tanto el pasado filosófico como la pretensión universalista y normativa de la naciente sociología, en oposición a supuestos que se describen como a-normativos. Desde esta perspectiva resulta oportuno establecer la conexión histórica de la sociología con su precedente pasado filosófico "para desde allí empezar a desentrañar algunas de las razones que llevan a la sociología a intentar resolver preocupaciones que no sólo desbordan su auto-comprensión científica, sino que también son constantemente reintroducidas" (Chernilo 2008:166). Dichas reintroducciones apuntarían a su continuo interés por generar explicaciones universales. Esta última intención resulta muy bien fundamentada por la influencia filosófica anidada en la llustración, que consistentemente se ve reflejada en el conjunto de las producciones científicas y morales que se promueven bajo un ideal de Razón Universal. Como otras disciplinas, "en tanto heredera crítica de las teorías del derecho natural del siglo XVII y la llustración del XVIII, la sociología adopta la pretensión universalista de ellas y no puede deshacerse de ese horizonte universalista" (Chernilo 2008:166), pues de alguna manera es justamente ése proyecto lo que entrega su razón de ser.

En este sentido es que se produce la introducción del análisis de las explicaciones que han preponderado en los planteamientos sociológicos, aunque en ningún caso monopólicamente. Es por esto que, si bien el positivismo mantiene una función emancipadora en tanto pretende colmar el abismo entre los individuos aislados y a unirlos en un verdadero universal (Comte 2010) sus respuestas sobre el conocimiento únicamente especializado llevan a que se pierda la pretensión y se llegue a una renuncia de universalismos generados por la abolición de la razón como organon unificador y los discursos tradicionales de la naturaleza, humana y material, en su lugar.

Orientado al contenido particular en lo dado, el positivismo renuncia a una visión universal en los términos de una teoría social en la medida que la naciente sociología privilegia una observación de existencias concretas en detrimento de un pensamiento abstracto más próximo a la reflexión filosófica y que surge de lo concreto para luego pretender un saber universal de lo social. En ese sentido, la tarea de establecer principios debiese ser una pretensión constante por reactualizar sus supuestos, no por dogmatizarlos. Así, si el fin de la trascendencia no supone el término de la universalidad, esto solo parece posible gracias a la configuración de fundamentos inmanentes.

Por tanto y sintetizando este apartado, cabría destacar que los cambios que constituyen al conocimiento, o a la forma de producir el conocimiento actual, nacerían de los cambios sustanciales que las sociedades producen y estabilizan. En ese sentido, la fragmentación y especialización del conocimiento coincidirían con la fragmentación y especialización de la sociedad. Solo así, en una interconectividad presente entre saber y realidad, se podría comenzar a cristalizar la base para una diferenciación entre sociología y teoría social.

\section{Conocimiento moderno y razón objetiva en lugar de universal}

El hecho básico que hemos venido desarrollando en torno a una parcelación del conocimiento como fruto de las condiciones sociales modernas, puede ser analogado al fenómeno no menos moderno de la instrumentalización de la razón. Puesto que la función de la razón pasa a ser monopolizada por su imperativo instrumental, el conocimiento mismo se transforma en herramienta útil para la dominación natural y social, y no como plano integrativo de la realidad. 
Horkheimer y Adorno, siguiendo a Nietzsche, dan cuenta de éste fenómeno como punto de inicio para la consideración de la pérdida de un ideal regulativo de la sociedad por medio de un supuesto de razón inmanente a la realidad. En este sentido el mito que rompe la llustración se vuelve punto de base para la vuelta a la mitología que en Nietzsche es resaltada por medio del arte, mientras que Horkheimer y Adorno se niegan a retornar a un presupuesto mítico-genético para quedarse en una especie de punto muerto gracias a una crítica radicalizada ya desde el propio Nietzsche (Habermas 1989:135-162).

En Crítica de la Razón Instrumental Max Horkheimer da cuenta del proceso gnoseológico que ha llevado a la modernidad a un plano en el cual sus condiciones estructurales permean el desarrollo de las bases del conocimiento para transformarlo en materia de suposición dominantemente práctica. Esto indudablemente redundaría en el escepticismo de cualquier pretensión de validar al conocimiento como fuente direccional de la realidad. Este hecho lleva a Horkheimer a señalar cómo particularmente la teoría ha perdido cualquier capacidad de orientación en la vida práctica de los humanos, principalmente por su postura acomodaticia al orden de lo establecido. En este plano Horkheimer concibe la dualidad entre una teoría tradicional que se nutre y glorifica en lo dado, y una teoría crítica que no descansa en su pretensión de revalidar a la razón como principio fundante y conducente de la sociedad. El universalismo otorgado por la razón versus el particularismo del conocimiento científico moderno, adquieren en Horkheimer un nuevo impulso en el momento en que se proyecta nuevamente una integración de la modernidad a través del reconocimiento de su incorrecto devenir.

Según Horkheimer la teoría tradicional, tanto en ciencias sociales como naturales, supone un concepto igual de teoría a partir del cual hacer teorías generales resulta ocioso, pues existe la convicción instalada de que lo mejor es hacer pequeñas reflexiones sobre un campo determinado en base al material obtenido (Horkheimer 2003:226). En esta línea, confeccionar explicaciones que incorporen al fenómeno estudiado como parte integrante de un todo mayor que le otorga su sentido, resultaría pernicioso para comprender en su originalidad su propia emergencia.

Horkheimer advierte que la transformación de las estructuras científicas dependa de la situación social respectiva es un hecho constatable en teorías tan generales como el sistema copernicano y a su vez también en problemas específicos de la investigación corriente: "La ilusión de independencia que ofrecen procesos de trabajo cuyos resultados, según se pretende, derivarían de la íntima esencia de su objeto, corresponde a la libertad aparente de los sujetos económicos en la sociedad burguesa" (Horkheimer 2003:231). De ahí que la noción de conocimientos inmutables lleve a cuestionar también los presupuestos del idealismo, particularmente kantiano. Horkheimer cree en la constitución de la realidad en el sujeto, pero mediada socialmente. Esto último desarrollaría la primacía de la sociedad como constitutiva de realidad.

Si la sensibilidad es pasiva y el entendimiento activo y este último bajo sus reglas "construye" su noción de realidad, ¿cómo puede estar seguro el entendimiento de poder aprehender bajo sus reglas la realidad del mundo? La solución kantiana señala que los fenómenos sensibles ya están formados por el sujeto trascendental cuando son captados por la percepción y juzgados con conciencia. Con ello señala que con toda la actividad racional otorgada al sujeto, aún queda un espacio irracional, no descubierto, que predispone el saber individual. Horkheimer está de acuerdo, ofreciendo la siguiente salida a esto aún "no descubierto": el doble carácter de los conceptos kantianos señalando unidad y racionalidad de una parte, y oscuridad, inconciencia, impenetrabilidad de otra, reflejan el actuar contradictorio de la actividad humana moderna. 
Esta contradicción queda resuelta cuando reconocemos que es la acción humana conjunta lo que forma la razón, pero al mismo tiempo generando que este proceso y sus resultados sean para los humanos algo extraño. En Kant el problema queda resuelto como una circunstancia necesaria: la contradicción entre actividad y pasividad no es una insuficiencia subjetiva sino algo realmente necesario, propio de la capacidad cognoscitiva. Hegel solucionará tal tensión con la disolución de la contradicción como valoración negativa en el espíritu absoluto. Horkheimer adiciona otro planteamiento: "la existencia de un comportamiento humano que tiene por objeto la sociedad misma, es la actividad crítica" (2003:239) entendiendo por ella la no adaptación irreflexiva al orden social propuesto. La separación tradicional de sujeto y objeto, lleva a que la identidad de lo conocido esté puesta en el futuro y no en el presente. El método conducente a ello en la terminología cartesiana, se denomina clarificación: en la teoría crítica significa no sólo un proceso lógico, sino también histórico concreto. En su curso se "transforman la estructura social y el teórico; es decir, se transforma el sujeto y el papel del pensamiento" (Horkheimer 2003:243).

Aun cuando hay adopciones claves de Hegel, Horkheimer toma distancia en varios puntos centrales de la filosofía hegeliana: un sistema que admitía cada opinión contradictoria como parte de la "verdad total" tenía inevitablemente implicaciones quietistas, ya que podía servir muy bien como teodicea justificativa del status quo (Jay 1989:91). Igual de crítico fue con la suposición contraria, extremista, del positivismo, el cual despojó al intelecto de la posibilidad de juzgar lo real como falso o verdadero, desarrollando una apoteosis de los hechos.

Según Martin Jay, en estas disidencias es donde radica la fuerza del argumento horkheimeriano: "la resistencia a sucumbir a una sistematización metafísica o a un empirismo antinómico, le dio a la Teoría Crítica su eficacia" (1989:93). A grandes rasgos, la apuesta de Horkheimer apunta a que la actual crisis de la razón consiste fundamentalmente en el hecho de que el pensamiento llegado a cierta etapa, "o bien ha perdido la facultad de concebir, en general, una objetividad semejante o bien comenzó a combatirla como ilusión. Este proceso se extendió paulatinamente, abarcando el contenido objetivo de todo concepto racional. Finalmente, ninguna realidad en particular puede aparecer per sé como racional, vaciadas de su contenido, todas las nociones fundamentales se han convertido en meros envoltorios formales. Al subjetivizarse, la razón se formaliza" (Horkheimer 1973:25).

A la luz de lo anterior, Horkheimer realiza un camino histórico para describir las diversas nociones que el concepto de razón ha adquirido en diferentes períodos. En ese recorrido, se hace posible concluir que la razón aparece totalmente sujeta al proceso social, para llegar en la actualidad a que su valor operativo, es decir, el papel que desempeña en el dominio sobre los hombres y la naturaleza, se haya convertido en criterio exclusivo. En este punto nuevamente se hace presente la noción de instrumentalización de la razón. Horkheimer se pregunta explícitamente por cuáles son las consecuencias de la formalización de la razón, "[n]ociones como las de justicia, igualdad, felicidad, tolerancia, que en siglos anteriores son consideradas inherentes a la razón o dependientes de ella, han perdido sus raíces espirituales. Son todavía metas y fines, pero no hay ninguna instancia racional autorizada a entregarles un valor y a vincularlas con una realidad objetiva" (1973:34). En otras palabras, remata Horkheimer, "la afirmación de que la justicia y la libertad son de por sí mejores que la injusticia y la opresión, no es científicamente verificable, y, por lo tanto, resulta inútil cualquier intento de objetivación racional" (1973:35). Así queda establecido que en último término, la formalización de la razón implica principalmente la pérdida de su contenido material.

Ahora bien, tampoco se debería caer en una deificación de la razón. La razón no debe ser juzgada como un ideal trascendente, existente fuera de la historia. A través de Horkheimer el Institut fur Sozialforschung 
insistió en reiteradas ocasiones en que la verdad "no era una categoría inmutable. Sin embargo, no por ello se debía caer en un relativismo" (Jay 1989:116), pues como hemos visto, toda época tiene su propia verdad. Así Horkheimer introduce, a grandes rasgos, tres características clave a la visión teórica del conocimiento: 1) incorporar siempre la noción de totalidad al estudio de fenómenos particularizados; 2) integrar el componente histórico a todo develamiento del saber; 3) reconocer la negativa instrumentalización del conocimiento en vistas a desarrollar orientaciones guía para una determinada práctica.

Por último, lo que Horkheimer critica en el fondo es el hecho de que la ciencia tradicional supone objetividad al plantear la sumisión de la teoría a los hechos, al tiempo que no es capaz de creer en una pretensión de razón objetiva habilitada para dar sentidos generales a la realidad. La aporía por tanto se funda en que el conocimiento moderno se jacta de encontrar objetividad y universalidad en el hecho de subsumirse al plano de los datos concretos, sin hacerse cargo de una efectiva objetividad y universalidad ancladas en la capacidad de una razón que permita orientar de modo inmanente la existencia relacional del humano consigo mismo y la naturaleza. El conocimiento moderno consiente el relativismo moral del uso del saber apelando a la existencia de hechos objetivos que solo permiten conclusiones especializadas de ciertos fenómenos, al tiempo que niega la posibilidad de unir todos esos saberes aislados en una consideración general, ahogando con ello a su vez la alternativa efectiva de generar una razón integrante con pretensiones de validez universal.

En otra línea y bajo el concepto de modernización de Max Weber, se aloja una noción que da vida a dicho concepto como una etapa desgajada de sus orígenes europeos, para convertirla en un patrón de procesos de evolución social universales, es decir, no limitados espacial o temporalmente. A esto es lo que se denomina la "paradoja del surgimiento de la modernidad, la cual se ancla espacial, temporal y culturalmente, pero con horizontes y alcances universales" (Chernilo y Mascareño 2005:23). Esta definición, apunta Habermas, rompe con la conexión interna entre racionalismo occidental y modernidad -relación absolutamente cierta por lo demás- de modo que la modernidad no pueda presentarse como objetivación histórica de "estructuras racionales, quedando estigmatizada como una culminación o remate, sino que más generalmente como teoría de la evolución" (Habermas 1989:12). Justamente el desprendimiento de su origen histórico para posarse en un pedestal universal, le otorga a la modernidad la pauta para autonomizarse y concebirse como un proceso de carácter social y autárquico. Como la pérdida de supuestos de universalidad en el conocimiento es una muestra del trayecto mismo de la modernidad, se justificaría reconstruir cómo o por qué la modernidad presenta más interrogantes, y en este sentido más problemas, que respuestas y soluciones.

Este proceso se hace patente gracias a la pérdida de un ideal regulativo que colmase la necesidad de cohesión social previo al surgimiento de la razón ilustrada. Las fuerzas religiosas que antaño operaron la integración social, dice Habermas, "quedan paralizadas a consecuencia del progresivo avance de la Ilustración que, dado que no se ha producido de forma arbitraria, tampoco puede ser objeto de abolición" (1989:110). Profundiza señalando que a la Ilustración le es propia la irreversibilidad de procesos de aprendizaje, que se funden en que las ideas no pueden olvidarse a voluntad, sino que solo pueden reprimirse o ser corregidas por ideas mejores. Con esto queda de manifiesto que el paso de la «infancia» a la "adultez» en el pensamiento humano figura como un continuo irrevocable, al cual no se puede renunciar una vez liberado, sino tan solo perfeccionar. En ese sentido el precepto que orienta una pretensión de solidaridad social recuperada solo puede ser encontrado al interior del horizonte de racionalización propiciado por la nueva época heredera del iluminismo. En palabras de Habermas, "de ahí que la ilustración sólo pueda remediar sus déficit mediante una radicalización de sí misma, mediante una 
ilustración radicalizada. De ahí que Hegel y sus discípulos hubieran de poner su esperanza en una dialéctica de la ilustración que hace valer a la razón como equivalente del poder unificante de la religión" (1989:13).

El argumento anterior va en la misma línea de la propuesta weberiana que señala en La Ciencia como Vocación, el diagnóstico de la emergencia de antiguos poderes impersonales tras el desencantamiento de las imágenes religiosas y metafísicas del mundo en la modernidad. En ese texto Weber nos hace conscientes de la nueva cara de la razón, ya no como ideal trascendente y regulativo de la realidad, por más que eso se pretendiese en el comienzo ilustrado como apunta Habermas, sino que ahora se yergue como herramienta que, al servicio del desencantamiento del mundo, propicia la instrumentalización impersonalizada de poderes de dominación, tanto hacia la naturaleza como hacia el propio ser humano. Por tanto el paso decisivo a esta consideración de la nueva labor del conocimiento es la conclusión del dominio de la razón en el plano instrumental. Así la nueva impersonalidad del poder humano tiene su origen en la instrumentalización de la razón. Este plano será el mismo que Horkheimer y Adorno pretendieron demostrar como un fenómeno que abarca las principales creaciones modernas: la ciencia experimental, el canon jurídico universal y el arte autónomo.

Según Habermas, con el concepto de "razón instrumental» Horkheimer y Adorno pretenden sacar las cuentas a un entendimiento calculante que ha usurpado el puesto a la razón. Este concepto "tiene también la función de recordar que la "racionalidad con arreglo a fines» levantada a totalidad, borra la distinción entre aquello que reclama validez y aquello que es útil para la autoconservación, echando abajo las barreras entre validez y poder, anulando aquella distinción categorial a la que la comprensión moderna del mundo creía deber una definitiva [e ilimitada] superación del mito" (Habermas 1989:149). De esta manera, "la razón, en tanto que instrumental, se ha asimilado al poder, renunciando con ello a su fuerza crítica" (1989:149) en los términos de un pensamiento que no se preocupa ya por detentar principios universales, sino únicamente particulares y contingentes.

La dialéctica de la llustración consistiría por tanto en la precisión de describir la autodestrucción de la capacidad crítica en términos de una ruptura con pretensiones de validez universales, generando aquél diagnóstico bajo un supuesto paradójico, ya que en el instante en que se efectúa tal descripción no se tiene más remedio que seguir haciendo uso de la crítica que se declara muerta. Se denuncia la conversión de la ilustración en totalitaria, con los propios medios de la ilustración, como apunta Habermas. Esta pérdida de confianza en la razón no solo se plantea en términos epistemológicos, sino principalmente como el vacío de un ideal integrador de la realidad. El destrono de la religión como órgano integrativo que en algún momento se creyó resultado de una suplantación racional, queda puesto en evidencia como falso en la medida que se constata el hecho de que la modernidad no ha logrado sellar las fragmentaciones que su advenimiento produjo. En ese sentido, antes que Horkheimer y Adorno, "Nietzsche da a entender a una modernidad abandonada de Dios el precio que en energías de solidaridad social ha tenido que pagar en el curso de su propio progreso" (Habermas 1989:167).

La importancia de la revitalización de la razón, a la luz de los argumentos horkheimerianos, como base para estabilizar nuevamente la pretensión de universalidad del conocimiento, radica por un lado en la propia explicación universal y en otro por la oposición que representa al conjunto de planteamientos técnicos y particulares que no dan cuenta de una comprensión holística y orientadora de la realidad. Como hemos visto, el surgimiento de un saber sobre lo social preponderantemente anclado en el positivismo decimonónico explica en parte la obtención que la sociología adopta en la no pretensión de lograr, en primer término, explicaciones universales. Si bien es innegable que existen teorías con una pretensión de universalidad más o menos clara, como la del propio Weber, la teoría social en su generalidad, opta, al 
igual que las demás esferas de la realidad social, por renunciar a un ideal explicativo integrador. Las más recientes sociologías generales como las de Niklas Luhmann o Pierre Bourdieu, representan una clara excepción a esta regla, cada cual con sus propias especificidades. Sin embargo, por otro lado, ninguna de ellas podría a su vez concebirse como un discurso sobre las relaciones humanas y la constitución de la sociedad en términos universales. Si consideramos que el planteo de la creciente relativización que, como hemos detectado surge del positivismo decimonónico, es esencialmente fruto de un estado determinado de las condiciones sociales, podemos mantener la afirmación de que las explicaciones sociales-que cruzan igualmente tanto a la moral como a la política, la economía o la ciencia- se orientan principalmente bajo un principio de explicación histórica. Y esto precisamente por la imposibilidad de evitar una relación con la historia.

En un ensayo titulado Del Sentido de la Historia Karl Löwith plantea cómo la modernidad es la primera época en que se comienza a pensar la historia como un «hacia dónde» en vez de un «por qué». Las épocas pasadas todavía se sentían dominadas por fuerzas caóticas en el devenir histórico por más que existieran intentos, principalmente ligados al cristianismo, de darle un sentido escatológico. Con la consideración hegeliana de una progresiva entrada de la "conciencia de libertad en el mundo" se percibe a la historia como un continuo creciente de razón, el cual lleva a concebir el pasado como antesala necesaria del presente y no como acontecimientos absurdos.

Esto permite al historiador moderno establecer la pregunta de «hacia dónde» camina la historia por sobre un impotente "por qué» es de tal o cual manera. Según Löwith, el historiador moderno hace la misma pregunta que Tocqueville en la introducción a La Democratie en Amérique de 1835: Où allons-nous donc? ¿Hacia dónde vamos?, "mientras que el historiador clásico preguntaba: ¿cómo llegó a ocurrir?" (Löwith 1998:321). Por esto la reconsideración de la razón como órgano integrativo de la realidad, apunta a establecer el mismo principio que Löwith le adjudica al historiador moderno: la razón cumple un rol como orientadora teleológica en relación al curso que debe seguir o pretender la sociedad. Cualquier atisbo por autonomizar la realidad como sistema autocrático, va en la línea de contradecir los supuestos básicos de la modernidad-preconizados antes, pero principalmente desde la llustración-referentes a la conducción de la historia humana, por medio de objetivos planteados racionalmente. Dejar, por así decir, el devenir moderno a su propia lógica mutilaría cualquier intento por darle un sentido humano a la dirección de la historia, con ello ahogando las posibilidades que pudiesen concebirse para procesos futuros.

De lo anterior se desprende que la necesidad de establecer un conocimiento que integre la multiplicidad de conexiones de la realidad moderna, se aloje en alguna de las explicaciones que la modernidad desarrolla de sí misma. La tradición de pensamiento occidental ha concluido bajo el concepto de sociedad ese cúmulo de relaciones que conforman compleja e interdependientemente la totalidad de las esferas que componen la vida social. Este concepto llevado a la categoría de objeto permite abordar la realidad desde sus numerosos compartimentos. A la luz de los argumentos que apelan a la constitución de una modernidad que no encuentra un horizonte de sentido satisfactorio en universalizar explicaciones, pues ello supondría validar ciertos principios que parecen estar más acordes antes con eslabones subjetivos que objetivos, la ciencia que se aboca al estudio de la sociedad aportaría una constante revitalización de una frontera explicativa universal, pues su quehacer se fundaría en gran medida en la comprensión de aquél fenómeno que una vez aparecido se transforma en meta y medida del mundo contemporáneo, a saber, la misma modernidad. Todos aquellos acontecimientos subalternos de la modernidad potencialmente podrían ser explicados por la fundamentación sociológica. De ahí que una de las bases de la sociología se asiente en la capacidad que ella posea para generar tipos de explicaciones universales, y no puramente atomizadas o particulares -sin por ello negar que ellas sean el paso previo a las generalizaciones de carácter universal. 
El elemento de disidencia intelectual que surgió, por ejemplo, con la filosofía de la existencia -que en último término tiene una raíz común con el marxismo, a saber, la negación de la realidad tal como ha terminado configurada- es una muestra más del malestar que significa el concebir un nuevo mundo donde la integración social viene dada por mecanismos de socialización desubjetivados. Justamente lo que se plantea desde el existencialismo es una revitalización del individuo como punto de base para configurar una trascendencia, del mismo modo que se pretende en la actualidad. No obstante, más allá del argumento existencialista, lo interesante es reparar en la desobediencia con que la filosofía continúa la pretensión por generar parámetros universales de comprensión, a fin de otorgar ciertos pilares en la orientación de la vida fundados en la razón. Cuestión a parte y que requeriría un estudio por sí mismo es ver si esto no es precisamente el objetivo de la filosofía en cuanto reflexión sobre los supuestos de todo conocimiento. Solo por mencionar un argumento a favor de esta idea, Löwith señala: "si bien la filosofía se produce en contraposición a la religión, esto sólo ocurre porque ella misma también está a la busca de una ser-en-sí absoluto. Pues sin la trascendencia, tanto la orientación en el mundo como la dilucidación de la existencia perderían su sentido definitivo y su profundidad" (1998:20).

\section{Apreciaciones finales: autoobservación de la sociedad moderna}

Recapitulando lo que hasta acá hemos recorrido, podemos concluir que lo que ocurre con la filosofía al culminar el idealismo es la adopción que hacen sus discípulos del sistema hegeliano, fundando con ello la emergencia de una teoría social que posteriormente es heredada por un positivismo con modelos de conocimiento provenientes de la ciencia natural bajo el concepto de sociología, con claras muestras de un proceso de racionalización que empieza a instalarse en el mundo moderno desde la llustración y que adicional y paradójicamente- comienza a perder la fe inicial en la razón como ideal integrativo en la realidad material como intelectual que se encontraba a la base del proyecto positivo de la emergente ciencia de la sociedad.

Incluso el planteamiento puede ir más lejos al señalar que uno de los puntos fundantes para rematar la creencia en la razón como ideal integrativo, se aloja en la apología de los hechos que, con justa razón, la ciencia moderna comienza a implementar. El problema se anidaría en que el pragmatismo que acompañó al surgimiento de la ciencia opacó la posibilidad de otorgarle respuestas universales a la misma, dando pie a sentencias con orientación contingente. Ello, extrapolado a nuestros días, podría traducirse en la pérdida de explicaciones filosóficas y científicas -sociológicas-que supongan una pretensión de validez universal.

En último término lo que se aprecia en el mundo moderno podría definirse como una búsqueda por la obtención de conocimiento que se supone necesaria en sí, en detrimento de la orientación que se le otorga a dicho conocimiento. Cabe preguntarse por la necesidad o no de un argumento que posicione tipos de explicación de la sociedad que generen una autoobservación que no suponga únicamente, ni en primer lugar, una utilidad tal vez demasiado contingente, sino la explicación de una totalidad de la realidad social.

A grandes rasgos cuatro son las consecuencias extraíbles de ello:

1) Las respuestas que genera la ciencia, particularmente social, si bien no permiten establecer de modo definitivo o categórico una verdad inmutable y junto a ello una orientación descriptiva y normativa ahistórica, sí cabría interrogar la posibilidad de encontrar en su sentido la opción de utilizar sus respuestas como punto de partida para la conducción de la sociedad. Justamente en sus explicaciones se podrían encontrar las bases para orientar las preguntas que atañen al mundo contemporáneo de determinada manera, aun cuando esta posibilidad escape a las convenciones del rol mismo de la ciencia actual. 
2) Es posible desprender de lo anterior la necesidad epistemológica de conectar las condiciones de realidad con las creaciones teóricas, a fin de desarrollar el dibujo completo de un tipo de conocimiento particular al interior de un marco mayor de generalidad. Ello a su vez permitiría observar la conexión presente entre la teorización de la realidad y la realidad de dicha teorización.

3) Se hace factible distinguir que el conocimiento moderno consiente la paradoja de un uso del saber especializado, apelando a la existencia de realidades particulares que requieren explicaciones específicas, al tiempo que se reconoce la necesidad de ir más allá de lo específico para articular esos saberes en consideraciones más amplias o generales, ahogando, sin embargo, una alternativa efectiva de generar un discurso integrante con pretensiones de validez universal. Ejemplo de ello es la creciente necesidad de expertos en temas precisos que a la vez articulen sus conocimientos con otros especialistas bajo el marco de un trabajo multi, inter y/o transdisciplinario. La objetividad preponderante, por tanto, se anida en la sumisión a los datos específicos al mismo tiempo que exime cualquier posibilidad de otorgar principios objetivos de alcances y significaciones universales. Sin dramatizar la existencia de las contradicciones, no es menor la búsqueda por una alternativa a aquello que se presenta como obstáculo, por tanto la consideración de la problemática del conocimiento atomizado versus una pretensión universal, es el primer paso para la solución a dicha paradoja.

4) Por último, la autobservación de la modernidad supone, en tanto fenómeno de proporciones mundiales, una necesaria universalización de sus autoanálisis. La sociología, en tanto ciencia de la modernidad, se presenta como una herramienta principal para el desarrollo de dicha tarea, que sin embargo no es completa sin una teoría de lo social que vaya más allá (o acá) de la descripción sociológica.

\section{Bibliografía}

Adorno, T. W. 2001. Epistemología y ciencias sociales. Madrid: Cátedra.

Chernilo, D. y Mascareño, A. 2005. Universalismo, particularismo y sociedad mundial: obstáculos y perspectivas de la sociología en América Latina. Persona y Sociedad 19(3): 17-45.

Chernilo, D. 2008. Universalismo: reflexiones sobre los fundamentos filosóficos de la sociología. Revista de Sociología 22: 165-191. doi: 10.5354/0719-529X.2008.14490

Comte, A. 2000. Positive philosophy. Ontario: Batoche Books.

Durkheim, E. 2007. Les règles de la méthode sociologique. Paris: Presses universitaires de France.

Habermas, J. 1989. El discurso filosófico de la modernidad. Madrid: Taurus.

Horkheimer, M. 1973. Crítica de la razón instrumental. Buenos Aires: Editorial Sur.

Horkheimer, M. 2003. Teoría crítica. Buenos Aires: Amorrortu.

Jay, M. 1989. La imaginación dialéctica. Madrid: Taurus.

Löwith, K. 1998. El hombre en el centro de la historia. Barcelona: Herder. 
Marcuse, H. 1994. Razón y revolución. Barcelona: Altaya.

Tarde, G. 1999. Monadologie et sociologie. París: Les empêcheurs de penser en rond.

Tocqueville, A. 1835. De la democratie en l'Amérique. París: Pagnerre editeur.

Weber, M. 1997. Sobre la teoría de las ciencias sociales. Barcelona: Península.

Weber, M. 2000. El político y el científico. Madrid: Alianza.

Weisz, E. 2011. Max Weber: la racionalización del mundo como proceso histórico-universal. REIS 134: 107-124. doi:10.5477/cis/reis.134.107

Recibido el 13 Dic 2015

Aceptado el 3 Feb 2016 